\title{
Correspondence
}

\section{Increasing tidal volumes and PEEP is an effective method of alveolar recruitment}

To the Editor:

Atelectasis following general anesthesia (GA) is a regular finding caused by reduction in the functional residual capacity (FRC). ${ }^{1}$ Atelectasis decreases partial pressures of oxygen in arterial blood $\left(\mathrm{PaO}_{2}\right)$. Reduction in FRC correlates well with an increase in alveolar to arterial differences of partial pressures for oxygen $\left(\mathrm{PAO}_{2}-\mathrm{PaO}_{2}\right){ }^{2}$ This difference in $\mathrm{PAO}_{2}-\mathrm{PaO}_{2}$ changes with variation in the $\mathrm{FIO}_{2}$; however, ratio of alveolar to arterial oxygen partial pressures $\left(\mathrm{PaO}_{2} / \mathrm{FIO}_{2}\right)$ is less dependent on the $\mathrm{FIO}_{2} \cdot{ }^{3}$

In this study we observed the effect of alveolar recruitment by increasing tidal volume from $8-18$ $\mathrm{mL} \cdot \mathrm{kg}^{-1}$ (for ten breaths) along with a positive endexpiratory pressure (PEEP) of $5 \mathrm{~cm}$ of $\mathrm{H}_{2} \mathrm{O}$ on oxygenation during GA. Seventeen adults undergoing elective surgery, and operated in the supine position were included. Initial ventilator settings included a PEEP of $5 \mathrm{~cm} \mathrm{H}_{2} \mathrm{O}$. Arterial blood gas analysis (ABG) was performed at 30 (basal), 40, 60, 90 and $150 \mathrm{~min}$ following GA. Alveolar recruitment was applied after the basal ABG. Statistical analysis was performed using ANOVA. Mean peak inspiratory pressure and plateau pressure observed at the time of alveolar recruitment were $30.00 \pm 9.55 \mathrm{~cm} \mathrm{H}_{2} \mathrm{O}$ and $24.90 \pm 7.48 \mathrm{~cm}$ $\mathrm{H}_{2} \mathrm{O}$ respectively. Postoperative chest $x$-ray revealed no evidence of barotrauma.

Alveolar recruitment resulted in a significant increase in the $\mathrm{PaO}_{2}, \mathrm{PaO}_{2} / \mathrm{FIO}_{2}$ ratio and compliance along with a significant decrease in the $\mathrm{PAO}_{2}-\mathrm{PaO}_{2}$ during the study period (Table). Alveolar recruitment is an effective way of maintaining a desirable $\mathrm{PaO}_{2}$ during GA. Increasing the tidal volume from 8-18 $\mathrm{mL} \cdot \mathrm{kg}^{-1}\left(+\right.$ PEEP $5 \mathrm{~cm} \mathrm{H}_{2} \mathrm{O}$ ) was not associated with adverse events. Alveolar recruitment also results in better lung compliance - a prophylactic strategy for the prevention of lung injuries observed during mechanical ventilation.

\section{P.K. Singh MD}
A. Agarwal $\mathrm{MD}$
A. Gaur MD
D.A. Deepali DNB
C.K. Pandey MD
U. Singh PhD
Lucknow, India

\section{References}

1 Brismar B, Hedenstierna G, Lundquist H, Strandberg A, Svensson L, Tokics L. Pulmonary densities during anesthesia with muscular relaxation - a proposal of atelectasis. Anesthesiology 1985; 62: 422-8.

2 Hickey RF, Visick WD, Fairley HB, Fourcade HE. Effects of halothane anesthesia on functional residual capacity and alveolar-arterial oxygen tension difference. Anesthesiology 1973; 38: 20-4.

3 Doyle DJ. Arterial/alveolar oxygen tension ratio: a critical appraisal. Can Anaesth Soc J 1986; 33: 471-4.

\section{Burst suppression ratio is the only deter- minant for BIS values below 30}

To the Editor:

I read the article by Mérat et al. about bispectral index (BIS) monitoring and severe cerebral ischemia ${ }^{1}$ with interest.

TABLE $\mathrm{PaO}_{2}$, compliance $\left(\mathrm{mL} \cdot \mathrm{cm}^{-1} \mathrm{H}_{2} \mathrm{O}\right), \mathrm{PAO}_{2}-\mathrm{PaO}_{2}, \mathrm{PaO}_{2} / \mathrm{FiO}_{2}$ values (mean $\pm \mathrm{SD}$ ) at different time points. * Significant difference from basal value $P<0.05$.

\begin{tabular}{llllll}
\hline Variables & & \multicolumn{2}{c}{ Time in minutes following general anesthesia } \\
& Basal (30) & 40 & 60 & 90 & 150 \\
\hline $\mathrm{PaO}_{2}$ & $204.7 \pm 39$ & $285.8 \pm 45.3^{*}$ & $281.1 \pm 39.7^{*}$ & $275.5 \pm 43.3^{*}$ & $280.8^{*} 37.2^{*}$ \\
$\mathrm{PAO}_{2}-\mathrm{PaO}_{2}$ & $135.3 \pm 39$ & $54.2 \pm 45.3^{*}$ & $58.9 \pm 39.7^{*}$ & $64.5 \pm 43.3^{*}$ & $59.2^{*} 37.2^{*}$ \\
$\mathrm{PaO}_{2} / \mathrm{FIO}_{2}$ & $409.4 \pm 117$ & $571.6 \pm 135.9^{*}$ & $562.2 \pm 119.1^{*}$ & $551 \pm 129.9^{*}$ & $561.6 \pm 111.6^{*}$ \\
$\mathrm{Compliance}$ & $27.8 \pm 7.3$ & $33.5 \pm 6.1^{*}$ & $35.7 \pm 7.4^{*}$ & $39.26 \pm 0.5^{*}$ & $41.2_{ \pm}+4.4^{*}$ \\
\hline
\end{tabular}

